\title{
A vigilância sanitária no contexto da agricultura familiar
}

\section{Health surveillance in the context of family agriculture}

Vigilancia sanitaria en el contexto de la agricultura familiar

\author{
Giselly Nunes de Oliveira Franco ${ }^{1}$ \\ Jacqueline de Cássia Pinheiro Lima² \\ Kátia Eliane Santos Avelar ${ }^{3}$
}

\begin{abstract}
${ }^{1}$ Mestrado em Desenvolvimento Local pelo Centro Universitário Augusto Motta (UNISUAM). Especialista em Auditoria em Saúde pela Coordenadoria de Extensão, Pesquisa e Pós-Graduação da Faculdade do Futuro (FAF). Graduação em Enfermagem pela FAF. Atualmente, é especialista em Políticas Públicas e Gestão da Saúde da Secretaria Estadual de Saúde de Minas Gerais. E-mail: francogiselly0@gmail.com, ORCID: https://orcid.org/0000-0002-6630-5400
\end{abstract}

${ }^{2}$ Pós-doutorado em Cognição e Linguagem pela Universidade Estadual do Norte Fluminense (UENF) e em História pela Universidade do Estado do Rio de Janeiro (UERJ). Doutorado em Sociologia pelo Instituto Universitário de Pesquisas do Rio de Janeiro (IUPERJ). Mestrado em História Social da Cultura pela Pontifícia Universidade Católica do Rio de Janeiro (PUC-Rio). Graduação em História pela UERJ. Atualmente, é pesquisadora colaboradora do Programa de PósGraduação em Cognição e Linguagem da UENF. E-mail: jacapili.jl@gmail.com, ORCID: https://orcid.org/0000-0003-0153-8948

${ }^{3}$ Doutorado em Ciências pela Universidade Federal do Rio de Janeiro (UFRJ). Mestrado em Ciências Biológicas pela UFRJ. Graduada em Farmácia e Bioquímica pela Universidade Federal de Juiz de Fora (UFJF). Atualmente, é docente e pesquisadora do Programa de Pós-Graduação em Desenvolvimento Local do Centro Universitário Augusto Motta (UNISUAM). E-mail: katia.avelar@gmail.com, ORCID: https://orcid.org/0000-0002-7883-9442 
Resumo: A agricultura familiar contribui para a produção dos alimentos, pois mantém as pessoas no campo, promove a erradicação da fome e da pobreza, além de proteger o meio ambiente e favorecer o desenvolvimento sustentável. Mas um dos desafios para o agricultor familiar é o atendimento às exigências da legislação sanitária, que é primordial para o aumento e a qualificação da sua produção, por possibilitar o acesso a políticas públicas desenvolvidas para esse segmento de produção. Os dados utilizados no estudo foram compilados por meio de questionários de preenchimento compulsório provenientes da plataforma Formulário do Sistema Único de Saúde (FormSUS), após cada inspeção sanitária realizada no âmbito do Projeto Vigi-Risco, da Secretaria de Estado de Saúde de Minas Gerais (SES/MG). Os dados foram disponibilizados pela Diretoria de Alimentos da SES/MG, referente ao período de 2015 a 2018. O artigo apresenta os principais desafios da vigilância sanitária para o alcance do produtor da agricultura familiar, uma vez que muitos agricultores desconhecem as normas e os fundamentos da vigilância sanitária, o que dificulta o acesso às políticas públicas destinadas ao incentivo da produção familiar.

Palavras-chave: legislação sanitária; pequeno produtor; alimentos seguros.

\begin{abstract}
Family farming contributes to the production of food by keeping people in the countryside, promoting the eradication of hunger and poverty, in addition to protecting the environment and promoting sustainable development. However, one of the challenges for family farmers is to meet the requirements of health legislation, which is essential for increasing and qualifying their production, as it allows access to public policies developed for this segment of production. The data used in the study were compiled through compulsory questionnaires from the Form of the Brazilian National Health Service (FormSUS platform) after each health inspection carried out within the scope of the Vigi-Risco Project of the Minas Gerais State Department of Health (SES/MG). The data were made available by the Food Directorate of SES/MG for the period from 2015 to 2018. The article presents the main challenges of health surveillance for the reach of the producer of family farming, since many farmers are unaware of the rules and foundations of health surveillance, which makes it difficult to access public policies aimed at encouraging family production.
\end{abstract}

Keywords: health legislation; small producer; safe food.

Resumen: La agricultura familiar contribuye a la producción de alimentos, manteniendo a las personas en el campo, promoviendo la erradicación del hambre y la pobreza, además de proteger el medio ambiente y promover el desarrollo sostenible. Sin embargo, uno de los desafíos para los agricultores familiares es cumplir con los requisitos de la legislación sanitaria, fundamental para incrementar y calificar su producción, ya que permite el acceso a las políticas públicas desarrolladas para este segmento de la producción. Los datos utilizados en el estudio fueron recopilados a través de cuestionarios obligatorios de la plataforma Formulario del Sistema Único de Salud (FormSUS), luego de cada inspección sanitaria realizada en el ámbito del Proyecto Vigi-Risco, del Departamento de Salud del Estado de Minas Gerais (SES/MG). Los datos fueron puestos a disposición por la Dirección de Alimentos de SES/MG para el período de 2015 a 2018. El artículo presenta los principales desafíos de la vigilancia de la salud para el alcance del productor de agricultura familiar, ya que muchos agricultores desconocen las normas y fundamentos de la vigilancia de la salud, lo que dificulta el acceso a políticas públicas orientadas a incentivar la producción familiar.

Palabras clave: legislación sanitaria; pequeño productor; comida segura. 


\section{INTRODUÇÃO}

É indiscutível a participação da agricultura familiar no desenvolvimento de grande parte das regiões do Brasil e do país como um todo, pois ela contribui para a produção de grande parte dos alimentos, mantendo as pessoas no campo, além de promover atividades voltadas à erradicação da fome e da pobreza, proteção ambiental e desenvolvimento sustentável. O agricultor familiar tem uma relação particular com a terra, de cuidado e proteção, pois é sua maior fonte de renda, trabalho e moradia.

Os dados do censo agropecuário de 2017, realizado pelo Instituto Brasileiro de Geografia e Estatística (IBGE), identificaram que, do total de estabelecimentos agropecuários do país, quase 4 milhões (77\%) foram classificados como de agricultura familiar e foram responsáveis por $23 \%$ do valor da produção. Isso tudo ocupando uma área de aproximadamente 80 milhões de hectares, 23\% da área total agrícola do Brasil. Em 2017, a agricultura familiar ocupava 10,1 milhões de pessoas, representando $67 \%$ do total de trabalhadores ativos nos estabelecimentos agropecuários; ou seja, em uma década, houve uma diminuição no número dessas propriedades. Mesmo assim, a agricultura familiar ainda é a principal empregadora no campo. Tem mais de 15 milhões de trabalhadores e é ainda a base da economia de $90 \%$ dos municípios do país com até 20 mil habitantes (IBGE, 2017).

Diante desse contexto, intensificaram-se as preocupações com a agricultura familiar, no sentido de assegurar a produção de alimentos básicos e melhorar a segurança alimentar. No entanto o agricultor familiar carece ainda de conhecimentos acerca das legislações sanitárias, de informações para que possa acessar alguns programas de políticas públicas que são primordiais para aumentar e qualificar ainda mais a sua produção. Este artigo é uma revisão de literatura e apresenta também os dados compilados dos questionários de preenchimento compulsório da plataforma Formulário do Sistema Único de Saúde (FormSUS) ${ }^{1}$, do projeto Vigi-Risco

\footnotetext{
${ }^{1}$ É um serviço do Departamento de Informática do Sistema Único de Saúde (DATASUS) para a criação de formulários na Web. O FormSUS é um serviço de uso público, com normas de utilização definidas, compatíveis com a legislação e com a Política de1 Informação e Informática do SUS. Disponível em: http://formsus.datasus.gov.br/site/default.php
} 
da Secretaria Estadual de Saúde de Minas Gerais (SES-MG), gerados a partir das inspeções sanitárias realizadas pelas vigilâncias sanitárias estaduais ou municipais. O artigo teve o objetivo de apresentar algumas situações enfrentadas pelo produtor da agricultura familiar quanto ao atendimento à legislação sanitária.

\section{AGRICULTURA FAMILIAR NO BRASIL E EM MINAS GERAIS}

\subsection{Agricultura familiar}

É inegável que a agricultura familiar existe desde os primórdios da civilização e colonização das terras, quando o homem deixou de procurar e passou a produzir o seu próprio alimento junto à sua família (BORBA; CARVALHO; SANT'ANA, 2017).

Segundo Bergamim (2016), no Brasil, o conceito de agricultura familiar é ainda algo recente, sendo ela chamada também, por alguns autores, de agricultura de subsistência, de pequena produção ou de pobreza rural. A agricultura familiar foi reconhecida pela sua categoria social e produtiva apenas a partir dos anos de 1990, sendo criadas e implantadas políticas públicas a seu favor. Antes desse período, as políticas públicas eram direcionadas às grandes propriedades (ESQUERDO-SOUZA; BERGAMASCO, 2015).

De acordo com a legislação brasileira, a Lei Federal n. 11.326, de 24 de julho de 2006, que estabeleceu as diretrizes para a formulação da Política Nacional da Agricultura Familiar e Empreendimentos Familiares Rurais, considera-se agricultor familiar aquele que: (i) não detenha área maior que 4 módulos fiscais; (ii) utilize predominantemente mão de obra da própria família; (iii) possua a maior parte de sua renda obtida das atividades econômicas do empreendimento; (iv) dirija seu estabelecimento com sua família (BRASIL, 2006a).

Segundo Lamarche (1993), a agricultura familiar pode ser definida como unidade de produção agrícola que, independentemente do sistema sociopolítico do país, é sempre assegurada por explorações familiares, nas quais a família, o trabalho e a propriedade são os elementos centrais; e, conforme Veiga (1996), as vantagens deste segmento vão além da diversificação 
da produção, pois ele apresenta um perfil essencialmente distributivo e sustentável, bem como o fortalecimento dos agricultores e da relação (família, trabalho e propriedade).

Sob o aspecto do desenvolvimento sustentável da agricultura familiar, este é mensurado pela capacidade de satisfazer as necessidades humanas de maneira integrada aos aspectos sociais, ambientais e econômicos. Por isso, a necessidade de um equilíbrio nesses pontos para a garantia de renda ao produtor rural (TOMASETTO; LIMA; SHIKIDA, 2009). É importante ressaltar que, do ponto de vista social, por ser um sistema pouco mecanizado, demanda maior número de mão de obra e promove a inclusão social; além disso, com as discussões sobre o meio ambiente, na produção orgânica, os impactos são limitados (TOMASETTO; LIMA; SHIKIDA, 2009).

Este segmento econômico teve sua legitimação perante o Estado, em meados dos anos de 1990, com a criação do Programa Nacional de Fortalecimento da Agricultura Familiar (PRONAF), passando a ser agenda de diversas políticas públicas de desenvolvimento rural (GRISA, 2010). Assim, essa representa para o país e, em particular, para o estado de Minas Gerais, importância incontestável para a produção de alimentos, representando hoje a maioria da população que vive e trabalha no campo. Segundo o Censo Agropecuário 2017, do Instituto Brasileiro de Geografia e Estatística (IBGE), o potencial desse segmento pode ser medido pela expressiva quantidade de estabelecimentos rurais existentes: dos 607.557 estabelecimentos rurais de Minas Gerais, 72,72\%, ou 441.829, são da agricultura familiar. E, do montante de 1.836 .353 pessoas ocupadas na agropecuária, 59,02\%, ou 1.083.824, pertencem ao setor (IBGE, 2017).

Porém dados do relatório de atividades 2018, elaborado pela Empresa de Assistência Técnica e Extensão Rural de Minas Gerais (EMATER-MG), ressaltam que os agricultores familiares e suas organizações enfrentam vários desafios relacionados à gestão e comercialização da sua produção. Entre esses desafios, podemos mencionar o atendimento às exigências legais, as boas práticas de produção e de fabricação, organização e gestão. Esses desafios contribuem para que grande parte da agricultura familiar permaneça restrita aos mercados informais (EMATER-MG, 2018). 


\subsection{Agricultura familiar e a legislação sanitária}

O termo "vigilância sanitária" originou-se da denominação "polícia sanitária", órgão que, a partir do século XVIII, era o responsável pelo controle do exercício profissional na área da saúde e do saneamento (GERMANO; GERMANO, 2011). As ações de vigilância sanitária foram reconhecidas como a área mais antiga da Saúde Pública, que tinha como principal objetivo evitar a propagação de doenças e realizar fiscalizações, principalmente em cemitérios, embarcações e comércio de alimentos, tendo atualmente um maior destaque (COSTA, 2000).

Mas seu marco fundamental ocorreu no final da década de 1990, com a promulgação da nova Constituição da República Federativa do Brasil, em 1988, a qual estabeleceu, entre outros, a saúde como direito de todos e dever do Estado (FISCHER; MARINI; WINCK, 2016). A Constituição Federal estabeleceu também a competência do SUS para controlar e fiscalizar procedimentos, produtos e substâncias de interesse para a saúde, entre outros, e, também, fiscalizar e inspecionar alimentos, bebidas e águas para consumo humano (incisos I, IV e VI do art. 200) (BRASIL, 1988).

Em 19 de setembro de 1990, foi promulgada a Lei Orgânica da Saúde - a Lei n. 8080, que regulamenta o Sistema Único de Saúde (SUS) e dispõe sobre as condições para a promoção, proteção e recuperação da saúde, estabelecendo em seu art. 6ㅇq que estão incluídas, no campo de atuação do SUS, a vigilância epidemiológica, a vigilância sanitária e a saúde do trabalhador (BRASIL, 1990).

De acordo com o capítulo I, artigo 6으, parágrafo 1ํ, da Lei n. 8080/90, a vigilância sanitária é definida como "um conjunto de ações capaz de eliminar, diminuir ou prevenir riscos à saúde e de intervir nos problemas sanitários decorrentes do meio ambiente, da produção e circulação de bens e da prestação de serviços de interesse da saúde" (BRASIL, 1990). Em 1999, foi definido o Sistema Nacional de Vigilância Sanitária (SNVS) e criada a Agência Nacional de Vigilância Sanitária (BRASIL, 1999 ), como autarquia vinculada ao Ministério da Saúde, cuja finalidade, segundo a Lei n. 9.782, de 26 de janeiro de 1999, é "promover a proteção da saúde da população, por intermédio do controle sanitário da produção e da comercialização de 
produtos e serviços submetidos à vigilância sanitária" (BRASIL, 1999). Assim sendo, o campo de atuação da vigilância sanitária tornou-se vasto e comple$\mathrm{xo}$, pois envolvem os produtos e serviços ligados direta ou indiretamente à saúde, como medicamentos, alimentos, produtos para a saúde, em todos os níveis da cadeia produtiva e mercadológica, além dos serviços prestados à população e ao indivíduo (DE SETA; PEPE; COSTA, 2010).

Portanto a vigilância sanitária assume um papel fundamental para a operacionalização dessa política pública, sendo necessário o redirecionamento e o fortalecimento de suas ações, que constituem, assim, com vistas à proteção da saúde do consumidor, dentro da perspectiva do direito humano à alimentação e segurança alimentar.

Além disso, a segurança alimentar e nutricional vem ganhando expressivo espaço na agenda pública nas últimas décadas, pela importância intersetorial como política pública que prioriza os princípios do direito humano à alimentação adequada e à soberania alimentar (SCHOTTZ; CINTRÃO; SANTOS, 2014).

Nesse sentido, ações estratégicas têm sido desenvolvidas pela Política Nacional de Segurança Alimentar e Nutricional (PNSAN), estabelecida pela Lei n. 11.346 (BRASIL, 2006b), principalmente a partir do Programa de Aquisição de Alimentos (PAA) e do Programa Nacional de Alimentação Escolar (PNAE), que desde 2009 estabeleceram que 30\% dos recursos federais transferidos para estados e municípios fossem destinados à compra da agricultura familiar (SCHOTTZ; CINTRÃO; SANTOS, 2014). Assim sendo, as dificuldades para a legalização sanitária de produtos oriundos da agricultura familiar ganharam mais destaque e legitimidade, a partir do reconhecimento desse setor pela PNSAN.

Em 2006, a partir da implantação das leis que reconheciam as entidades do Microempreendedor Individual (MEI) e do agricultor familiar, a Lei Complementar n. 123/2006 e a Lei n. 11.326/2006, viu-se a paulatina adoção de políticas voltadas a esse modelo de produção (BORBA; CARVALHO; SANT'ANA, 2017). Nesse sentido, em 2011, a Agência Nacional de Vigilância Sanitária (ANVISA) integrou-se ao Plano Brasil Sem Miséria (BSM), criando o Programa de Inclusão Produtiva com Segurança Sanitária (PIPSS), que promoveu um debate com diversos setores governamentais e com a sociedade civil organizada. Um dos principais desdobramentos foi a aprovação, 
em 2013, da Resolução da Diretoria Colegiada n. 49 (RDC n. 49/13), que dispõe sobre a "regularização sanitária do microempreendedor individual, do empreendimento familiar rural e do empreendimento econômico solidário" (SCHOTTZ; CINTRÃO; SANTOS, 2014). Com a adoção do estímulo à regularização como política de governo, materializada na RDC n. 49/13, pela primeira vez, a ANVISA estabeleceu uma normativa voltada especificamente para este público, visando facilitar a sua formalização por meio da racionalização, simplificação e padronização dos procedimentos e requisitos para regularização sanitária (SCHOTTZ; CINTRÃO; SANTOS, 2014). Foi também a primeira vez que uma norma sanitária reconheceu a necessidade de proteger "a produção artesanal a fim de preservar costumes e conhecimentos tradicionais na perspectiva do multiculturalismo dos povos, comunidades tradicionais e agricultores familiares" (BRASIL, 2013).

Outro avanço importante enquanto estímulo à regularização dos pequenos produtores foi a política de governo estadual de Minas Gerais, que publicou a Resolução da Secretaria Estadual de Saúde de Minas Gerais, n. 6.362 , de 8 de agosto de 2018, a qual estabelece procedimentos para o licenciamento sanitário do microempreendedor individual, do empreendimento familiar rural e do empreendimento econômico solidário, que exercem atividades de baixo risco sanitário na área de Alimentos. Essa resolução leva em consideração as avaliações de risco nas inspeções sanitárias e nos processos de licenciamento da produção em pequena escala e, principalmente, da produção artesanal (MINAS GERAIS, 2018).

\subsection{Políticas públicas voltadas para a agricultura familiar}

Nas últimas décadas, houve uma valorização da agricultura familiar por meio de um conjunto de políticas públicas voltadas para o acesso ao mercado da pequena produção familiar - entre as quais, destacam-se o Programa Nacional de Alimentação Escolar (PNAE), o Programa de Aquisição de Alimentos (PAA) e o Programa Nacional de Fortalecimento da Agricultura Familiar (PRONAF), uma das primeiras políticas voltada aos pequenos produtores. Além dessas políticas que reforçam a produção de alimentos, o mercado apresenta também essa nova demanda dos consumidores, que 
está voltada para hábitos alimentares mais saudáveis (ESTEVAM; SALVARO; SANTOS, 2018).

Em setembro de 2015, representantes dos 193 Estados-Membros da Organização das Nações Unidas (ONU) criaram, em Nova York, um plano de ação para as pessoas, o planeta e a prosperidade, denominada Agenda 2030, comprometendo-se a tomarem medidas ousadas e transformadoras para promover o desenvolvimento sustentável até o ano de 2030. A Agenda é composta por 17 Objetivos do Desenvolvimento Sustentável (ODS) e 169 metas para erradicar a pobreza e promover vida digna para todos. Especificamente, o ODS 2 promove "Acabar com a fome, alcançar a segurança alimentar e melhoria da nutrição e promover a agricultura sustentável" (ONU, 2015). Entre as metas estabelecidas pela ONU para atingir esse objetivo, destaca-se a de "[...] dobrar a produtividade e a renda dos pequenos produtores de alimentos, particularmente mulheres, povos indígenas e agricultores familiares" (ONU, 2015). Dessa forma, percebe-se a importância de investimentos e instauração de políticas públicas voltadas para o desenvolvimento da agricultura familiar.

A condução e concepção das políticas públicas para a agricultura familiar eram institucionalmente atribuições do Ministério do Desenvolvimento Agrário (MDA), extinto em 2016, passando suas competências para a Secretaria Especial de Agricultura Familiar e do Desenvolvimento Agrário (SEAD), que se tornou em 2019 a Secretaria de Agricultura Familiar e Cooperativismo (SAF), vinculada ao Ministério da Agricultura, Pecuária e Abastecimento (MAPA).

O Quadro 1 apresenta algumas das principais políticas formuladas e executadas pelos órgãos governamentais responsáveis pela agricultura familiar.

Quadro 1 - Principais programas voltados para a agricultura familiar

\begin{tabular}{|c|c|l|}
\hline Programas & \multicolumn{1}{|c|}{ Área } & \multicolumn{1}{|c|}{ Objetivos } \\
\hline $\begin{array}{c}\text { Programa Nacional } \\
\text { de Fortalecimento } \\
\text { da Agricultura } \\
\text { Familiar (PRONAF) }\end{array}$ & $\begin{array}{c}\text { Crédito de Custeio } \\
\text { e Investimento }\end{array}$ & $\begin{array}{l}\text { Financiar projetos individuais ou cole- } \\
\text { tivos, que gerem renda aos agriculto- } \\
\text { res familiares e assentados da reforma } \\
\text { agrária. }\end{array}$ \\
\hline
\end{tabular}




\begin{tabular}{|c|c|c|}
\hline $\begin{array}{l}\text { Programa Nacional } \\
\text { de Crédito } \\
\text { Fundiário (PNCF) }\end{array}$ & $\begin{array}{l}\text { Crédito } \\
\text { Fundiário }\end{array}$ & $\begin{array}{l}\text { Oferecer condições para que os tra- } \\
\text { balhadores rurais sem-terra ou com } \\
\text { pouca terra (não mais do que um mó- } \\
\text { dulo rural) possam comprar um imóvel } \\
\text { rural por meio de um financiamento. }\end{array}$ \\
\hline $\begin{array}{c}\text { Seguro da } \\
\text { Agricultura } \\
\text { Familiar (SEAF) }\end{array}$ & $\begin{array}{l}\text { Seguro Rural e } \\
\text { Zoneamento } \\
\text { Agrícola }\end{array}$ & $\begin{array}{l}\text { Permitir ao agricultor familiar produzir } \\
\text { com segurança e com relativa garantia } \\
\text { de renda. }\end{array}$ \\
\hline $\begin{array}{l}\text { Programa de } \\
\text { Aquisição de } \\
\text { Alimento (PAA) }\end{array}$ & Comercialização & $\begin{array}{l}\text { Colaborar com o enfrentamento da } \\
\text { fome e da pobreza no Brasil e, ao } \\
\text { mesmo tempo, fortalecer a agricultura } \\
\text { familiar. Utilizar mecanismos de co- } \\
\text { mercialização que favoreçam a aquisi- } \\
\text { ção direta de produtos de agricultores } \\
\text { familiares ou de suas organizações, } \\
\text { estimulando o processo de agregação } \\
\text { de valor à produção. }\end{array}$ \\
\hline $\begin{array}{l}\text { Programa de } \\
\text { Garantia de Preços } \\
\text { para a Agricultura } \\
\text { Familiar (PGPAF) }\end{array}$ & Comercialização & $\begin{array}{l}\text { Garantir às famílias agricultoras que } \\
\text { acessam o PRONAF, em caso de baixa } \\
\text { de preços no mercado, um desconto } \\
\text { no pagamento do financiamento cor- } \\
\text { respondente à diferença entre os pre- } \\
\text { ços de mercado e o preço de garantia } \\
\text { do produto. }\end{array}$ \\
\hline $\begin{array}{c}\text { Programa Nacional } \\
\text { de Alimentação } \\
\text { Escolar (PNAE) }\end{array}$ & Comercialização & $\begin{array}{l}\text { Contribuir para o crescimento e o } \\
\text { desenvolvimento biopsicossocial, a } \\
\text { aprendizagem, o rendimento escolar } \\
\text { e a formação de práticas alimentares } \\
\text { saudáveis dos alunos, por meio de } \\
\text { ações de educação alimentar e nutri- } \\
\text { cionais e da oferta de refeições que } \\
\text { cubram as suas necessidades nutricio- } \\
\text { nais durante o período letivo. }\end{array}$ \\
\hline
\end{tabular}

Fonte: Moreira (2015).

\subsection{Mercado informal da agroindústria familiar}

A importância da agricultura familiar para o desenvolvimento da valorização do espaço rural tem interface com a informalidade e suas pequenas agroindústrias, sendo essa prática tão antiga quanto a própria 
agricultura familiar (FISCHER; MARINI; WINCK, 2016). O setor informal se caracteriza, segundo os autores supracitados por atividades cujos processos de produção, relações de trabalho, instalações, ausência de alvará sanitário e inadequação às normas e técnicas de produção não se enquadram aos padrões de regulação vigentes. Ou seja, "informal" são todas as atividades que não atendem integralmente às exigências das legislações propostas pelos órgãos institucionais nas quais estão inseridos.

Embora os agricultores familiares tenham sido reconhecidos como categoria a partir da década de 1990, eles enfrentam, ainda, grandes desafios para sair da informalidade, o que torna uma ameaça à sua própria continuidade, devido aos processos de produção não se enquadrarem às exigências das normatizações (WILKINSON; MIOR, 1999). Outra preocupação acerca da informalidade na produção e comercialização de alimentos está nos riscos que podem apresentar à saúde dos consumidores.

Entre os desafios enfrentados pelos agricultores familiares, podemos mencionar a falta de recursos educacionais, sociais, incerteza quanto ao êxito do negócio para investir na formalização do negócio e a burocracia excessiva (ESTEVAM; SALVARO; SANTOS, 2018). Esses autores acreditam que, entre todos os obstáculos, como os altos custos tributários e as dificuldades para manter a escala de produção, o principal seja o rigor da vigilância sanitária, que precisa ser superado pelos produtores para conseguirem alcançar a formalidade.

Em contrapartida, segundo Karnopp et al. (2019), essa legalização proporcionará vários benefícios, como: a valorização e melhora da qualidade dos produtos, possibilitando a ampliação do mercado por meio da comercialização, a não exclusão do mercado, a permanência dos filhos dos agricultores no meio rural, além da visibilidade social.

\section{METODOLOGIA}

Este artigo foi baseado em pesquisas bibliográficas, com uma abordagem quali-quantitativa, que, segundo Knechtel (2014), inclui técnicas que interpretam informações quantitativas por meio de dados numéricos (expressos neste artigo por meio de tabelas e gráficos para análises) e dados 
qualitativos, mediante observação e vivência da pesquisadora, interação participativa e interpretação dos discursos dos sujeitos.

Os dados foram disponibilizados pela Diretoria de Alimentos da Secretaria de Estado de Saúde de Minas Gerais (SES/MG), referentes ao período de 2015 a 2018. Teve como universo da pesquisa os municípios do Estado de Minas Gerais que possuem indústria de alimentos, às quais, pela primeira vez, em 2015, o formulário do FormSUS do Projeto Vigi-Risco permitiu a caracterização como "Agricultura Familiar ou Produtor Rural", o que contribuiu para dar visibilidade a essa categoria. Vale ressaltar que, antes de 2015, independentemente da forma de produção (industrializada, artesanal, processada), todos os estabelecimentos da área de alimentos, como padaria, sorveterias (gelados comestíveis), agricultura familiar ou produtor rural tinham a mesma classificação.

Os dados foram compilados por meio de questionários de preenchimento compulsório na plataforma FormSUS, após cada inspeção sanitária realizada no âmbito do Projeto Vigi-Risco, da Secretaria de Estado de Saúde de Minas Gerais, sendo disponibilizados pela SES/MG (2019).

\section{RESULTADOS E DISCUSSÃO}

É papel da Vigilância Sanitária o controle sanitário, entendido como aferição da qualidade dos produtos e a verificação das condições de licenciamento e funcionamento dos estabelecimentos por meio da inspeção, fiscalização, lavratura de autos e aplicação de penalidades, conforme descrito nos termos do artigo 70 da Lei n. 13.317/99, o Código de Saúde do Estado de Minas Gerais (MINAS GERAIS, 1999). Sendo assim, neste item, apresenta-se a situação dos agricultores familiares quanto à sua regularização perante a Vigilância Sanitária, no período de 2015 a 2018, em Minas Gerais.

Pode-se observar que, em 2015, quando o formulário do FormSUS permitiu a caracterização das indústrias de alimentos como "Agricultura Familiar ou Produtor Rural" das 1.211 (mil duzentas e onze) inspeções sanitárias realizadas nas "Indústrias de Alimentos", 658 (seiscentos e cinquenta e oito) estabelecimentos foram caracterizados como "Agricultura 
Familiar ou Produtor Rural", revelando que o número de produtores rurais ou da agricultura familiar era considerável, conforme ilustrado na Figura 1 (SES/MG, 2019).

Figura 1 - Número absoluto de inspeções realizadas em estabelecimentos caracterizados como Indústria de Alimentos no Estado de Minas Gerais, no ano de 2015

\section{5}

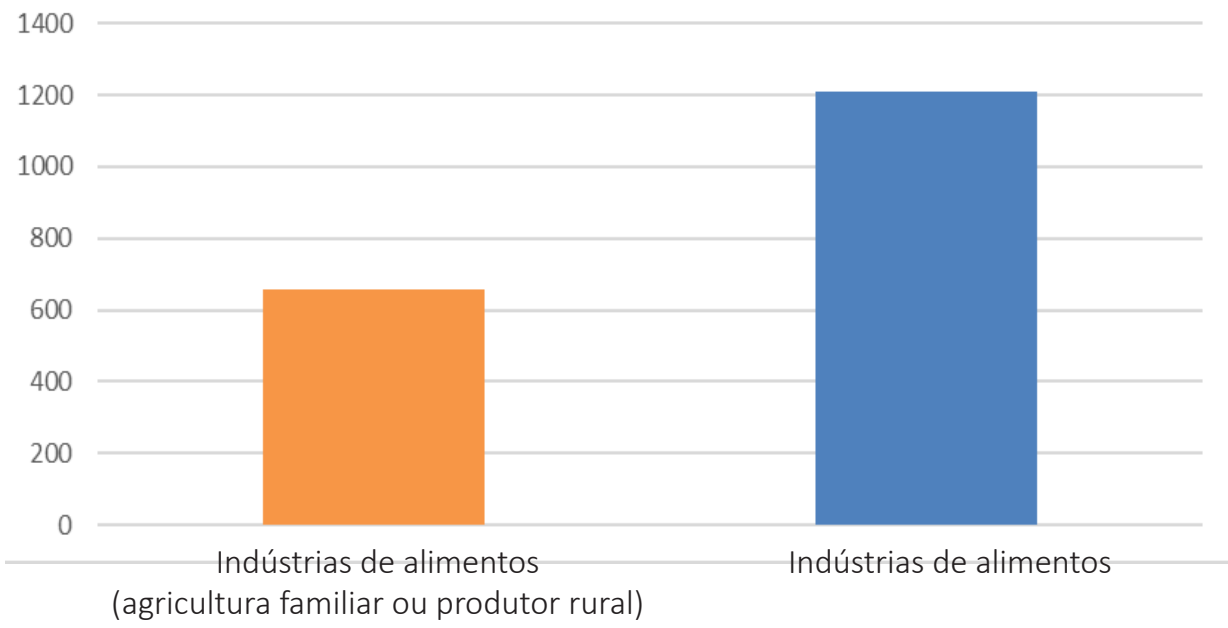

Fonte: SES/MG (2019).

Vale ressaltar que os estabelecimentos considerados como "Indústria de Alimentos", caracterizados como "Agricultura Familiar ou Produtor Rural", são sujeitos ao controle sanitário e são considerados estabelecimentos de serviço de interesse da saúde, por produzirem ou manipularem os alimentos, de acordo como art. 82, inciso I, da Lei n. 13.317/99, o Código de Saúde de Minas Gerais (SES/MG, 1999). E, quanto aos alimentos de origem vegetal, compete à Vigilância Sanitária inspecioná-los, enquanto aos de origem animal, cabe ao Instituto Mineiro de Agropecuária (IMA).

Ainda sobre o número de inspeções realizadas, observa-se que, em 2015, do total de 658 estabelecimentos caracterizados como "Indústria de Alimentos - Agricultura Familiar ou Produtor Rural", no Estado de Minas Gerais, somente 275 (duzentos e setenta e cinco) solicitaram licenciamento 
sanitário; ou seja, apenas $4 \%$ dos estabelecimentos manifestaram interesse em se regularizar, enquanto os outros 383 funcionaram irregularmente.

Conforme descrito no art. 85 da Lei n. 13.317/99, o Código de Saúde de Minas Gerais, os estabelecimentos sujeitos ao controle e à fiscalização sanitária terão o alvará sanitário expedido pela autoridade sanitária competente, municipal ou estadual, conforme habilitação e condição de gestão. O parágrafo 10 reforça ainda que a concessão ou a renovação do alvará sanitário ficarão condicionadas ao cumprimento de requisitos técnicos e à inspeção da autoridade sanitária competente (MINAS GERAIS, 1999).

Em 2016, esse número aumentou quase 25\%, correspondendo a 343 (trezentos e quarenta e três) solicitações. Em 2017, houve um aumento de 193,8\%, número 3 (três) vezes maior que do ano anterior, totalizando 1.008 (mil e oito) inspeções sanitárias. Em 2018, foram 1.197 (mil cento e noventa e sete) inspeções, sendo que 1.099 (mil e noventa e nove) informaram sobre o alvará sanitário, o que representa um avanço e interesse dos produtores rurais e da agricultura familiar em atender às exigências da legislação sanitária, conforme ilustra a Figura 2.

Figura 2 - Número absoluto de inspeções no Estado de Minas Gerais em estabelecimentos caracterizados como "Agricultura Familiar ou Produtor Rural", nos anos de 2015 a 2018

\section{0}

1000

800

600

400

200

0
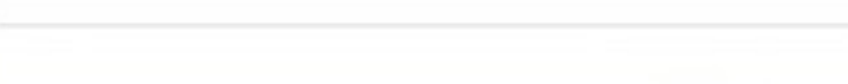
A Figura 3 representa a relação entre os percentuais de inspeções realizadas com a concessão ou não do alvará sanitário, no Estado de Minas Gerais, em estabelecimentos caracterizados como "Agricultura Familiar ou Produtor Rural", nos anos de 2015 a 2018.

Na análise do período de 2015 a 2018, observou-se que, em 2015, dos 658 (seiscentos e cinquenta e oito) estabelecimentos declarados como "Agricultura Familiar ou Produtor Rural", 275 (duzentos e setenta e cinco) solicitaram licenciamento sanitário. Desse montante, foram liberados 55\%, ou seja, 150 (cento e cinquenta) estabelecimentos obtiveram o licenciamento sanitário, enquanto 125 (cento e vinte e cinco), isto é, 45\%, não conseguiram o licenciamento por não terem cumprido os requisitos técnicos, como as boas práticas de fabricação, conforme exigido pela legislação sanitária.

No ano de 2016, houve um discreto aumento: dos 277 (duzentos e setenta e sete) estabelecimentos que solicitaram o licenciamento, 151 (cento e cinquenta e um) receberam a concessão, o que representa 55\% dos estabelecimentos. E não foram concedidos licenciamentos a 126 (cento e vinte e seis) estabelecimentos, o que representa 45\%. Em 2017, período em que houve um aumento considerável de inspeções, dos 848 (oitocentos e quarenta e oito) estabelecimentos, 641 (seiscentos e quarenta e um), ou seja, 64\%, receberam licenciamento. Entretanto não foram concedidos licenciamentos a 207 (duzentos e sete) estabelecimentos, isto é, a 36\%. Já no ano de 2018, dos 1.099 (mil e noventa e nove) estabelecimentos que solicitaram licenciamento, 835 (oitocentos e trinta e cinco), ou seja, 76\%, receberam a concessão, enquanto outros 264 (duzentos e sessenta e quatro), ou seja, $24 \%$, não a receberam. Os valores demonstram um crescimento no número de estabelecimentos que solicitaram o licenciamento, assim como um aumento na emissão dos alvarás sanitários emitidos, conforme evidenciado pelas Figuras 2 e 3.

Foi possível observar que o aumento de estabelecimentos que tiveram suas atividades regularizadas se deveu ao incentivo da política de governo materializada na RDC 49/13 da ANVISA e, posteriormente, na Resolução SES/MG n. 6362/2018, que levou em consideração as peculiaridades da pequena produção da agricultura familiar ou do produtor rural e, também, a produção artesanal. 
Figura 3 - Percentuais de inspeções em estabelecimentos caracterizados como "Agricultura Familiar ou Produtor Rural", com alvará concedido e não concedido, no Estado de Minas Gerais, de 2015 a 2018

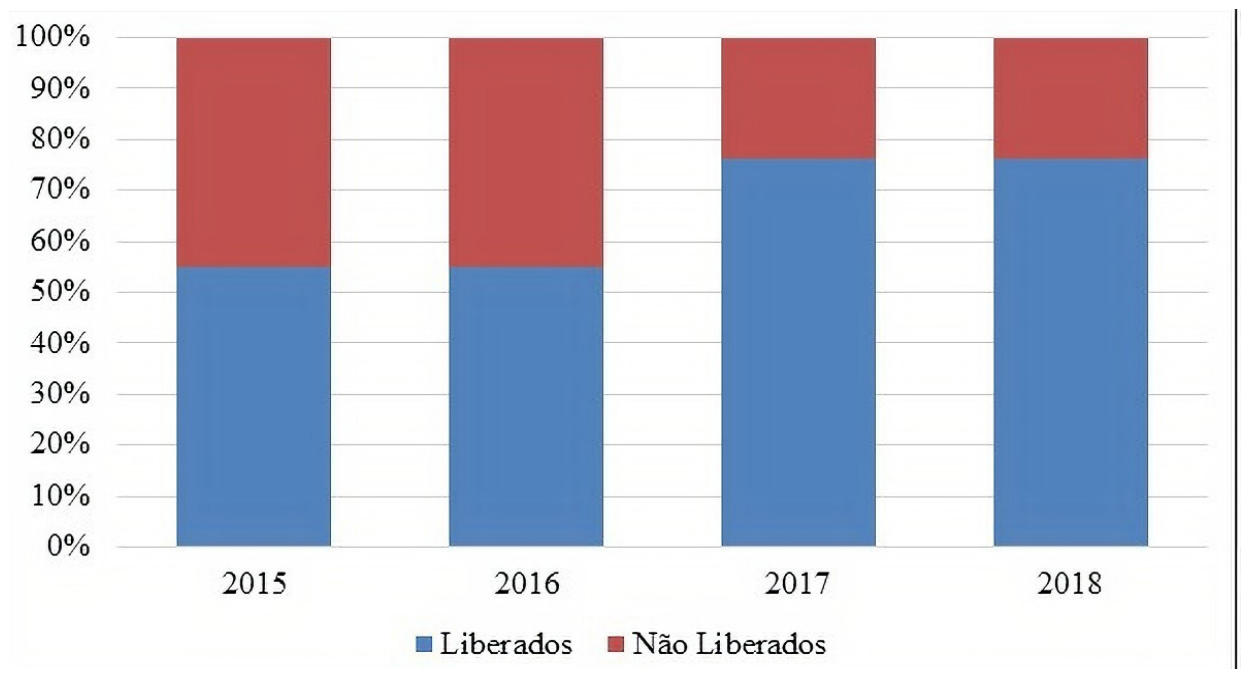

Fonte: SES/MG (2019).

Os dados apresentados neste estudo evidenciaram o avanço paulatino acerca da inclusão produtiva da agricultura familiar e sua adequação às exigências da vigilância sanitária no período de 2015 a 2018, em Minas Gerais. Isso contribuiu para a regularização dos estabelecimentos, assim como para a valorização e melhoria da qualidade dos produtos comercializados, revelando, assim, que o desafio em atender ao rigor da vigilância sanitária está sendo superado pelos agricultores familiares.

\section{CONSIDERAÇÕES FINAIS}

A agricultura familiar tem uma importância incontestável pela grande contribuição ao desenvolvimento econômico do país, não somente pela produção de alimentos, mas também para reduzir o êxodo rural, gerar emprego e renda. Além disso, garante a sustentabilidade do meio ambiente, preservando as características paisagísticas e melhorando a segurança alimentar. No entanto é importante a legalização sanitária das produções de alimentos artesanais e da agricultura familiar. 
Assim sendo, este artigo aborda os desafios da vigilância sanitária para o alcance do produtor da agricultura familiar, ao que se refere ao conhecimento e atendimento à legislação sanitária para a legalização dos seus produtos.

Entre as dificuldades para a legalização, ressaltamos que a regularização sanitária foi uma delas, identificada pelos produtores da agricultura familiar. Esse desafio foi justificado por vários autores, como a falta de conhecimento dos fundamentos da vigilância sanitária por parte do produtores, embora eles reconheçam a importância dela para a saúde e segurança alimentar. Além disso, a não regularização compromete também as possibilidades de acesso dos agricultores ao mercado de seus produtos e às políticas públicas de estímulo à agricultura familiar.

As normas sanitárias foram consideradas um avanço, além de necessárias para a saúde e segurança alimentar. Entretanto há agricultores que ainda não conhecem as normas e os fundamentos da vigilância sanitária, o que dificulta o acesso às diversas políticas públicas voltadas para o incentivo à produção familiar. O maior desafio é dar equilíbrio a essa situação, para que as normas possam ser efetivamente aplicadas sem comprometer as possibilidades de acesso dos produtos dos agricultores ao mercado.

Com base no estudo realizado, constatou-se que o atual momento é de transformação dos paradigmas no que se refere à busca pela regularização e atendimento às exigências da vigilância sanitária. Os dados analisados retratam uma tendência de ampliação da formalização e das adequações dos estabelecimentos da agricultura familiar. Sem dúvida, a adoção do estímulo à regularização materializada na RDC 49/2013 e na Resolução SES/MG n. 6362/2018 demonstrou que é possível a produção em menores escalas, com qualidade sanitária, adequação às normas e perspectiva real de inclusão no mercado. O que contribui para a visibilidade e formalização do pequeno produtor, além da expansão da produção de alimentos.

Entretanto a mudança de paradigma ainda não foi totalmente alcançada, pois há, ainda, agricultores que não se adequaram, o que demandará, principalmente dos serviços de vigilância sanitária, contínuas ações de 
educação sanitária e disseminação dos conceitos pertinentes às legislações sanitárias. Assim, a vigilância sanitária deve ser reconhecida muito além de prevenir riscos e evitar que as pessoas fiquem doentes, mas também como agente de desenvolvimento, capaz de estimular o mercado formal e auxiliar na distribuição de renda.

\section{REFERÊNCIAS}

BERGAMIM, J. S. Impactos ambientais e agricultura familiar: como esta relação apresenta-se no espaço rural paranaense. Ciência e Natura, Santa Maria, v. 38, n. 1, p. 206-14, abr. 2016.

BORBA, V. U.; CARVALHO, A. M. G.; SANT'ANA, R. C. G. agricultura familiar e políticas públicas: análise da fase de recuperação de dados sobre o PRONAF no Estado de São Paulo. In: SEMINÁRIO EM CIÊNCIA DA INFORMAÇÃO [SECIN], 7., 21-23 ago. 2017, Londrina. Anais [...]. Londrina: Universidade Estadual de Londrina, 2017. Disponível em: http://www.uel.br/eventos/cinf/index.php/secin2017/secin2107/ paper/viewFile/458/271. Acesso em: 22 nov. 2019.

BRASIL. Agência Nacional de Vigilância Sanitária [ANVS]. Resolução ANVISA. Resolução RDC n. 49, de 31 outubro de 2013. Dispõe sobre a regularização para o exercício de atividade de interesse sanitário do microempreendedor individual, do empreendimento familiar rural e do empreendimento econômico solidário e dá outras providências. Diário Oficial da República Federativa do Brasil. Brasília-DF, 31 out. 2013. Disponível em: https://bvsms.saude.gov.br/bvs/saudelegis/anvisa/2013/ rdc0049_31_10_2013.html. Acesso em: 5 nov. 2019.

BRASIL. Lei n. 11.326, de 24 de julho de 2006. Estabelece as diretrizes para a formulação da Política Nacional da Agricultura Familiar e Empreendimentos Familiares Rurais. Diário Oficial da República Federativa do Brasil. Brasília-DF, 24 de julho de 2006, 2006a. Disponível em: http://www.planalto.gov.br/ccivil_03/_ Ato2004-2006/2006/Lei/L11326.htm. Acesso em: 10 out. 2019.

BRASIL. Lei n. 11.346, de 15 de setembro de 2006. Lei de Segurança Alimentar e Nutricional. Brasília-DF, 2006b. Disponível em: http://www.planalto.gov.br/ ccivil_03/_Ato2004-2006/2006/Lei/L11346.htm. Acesso em: 10 out. 2019.

BRASIL. Lei n. 9.782, de 26 de janeiro de 1999. Define o Sistema Nacional de Vigilância Sanitária, cria a Agência Nacional de Vigilância Sanitária, e dá outras providências. Diário Oficial da República Federativa do Brasil. Brasília-DF, 26 de 
janeiro de 1999. Disponível em: http://www.planalto.gov.br/ccivil_03/leis/L9782. htm. Acesso em: 1으on. 2019.

BRASIL. Lei n. 8.080, de 19 de setembro de 1990. Dispõe sobre as condições para a promoção, proteção e recuperação da saúde, a organização e o funcionamento dos serviços correspondentes e dá outras providências. Diário Oficial da República Federativa do Brasil. Brasília-DF, 19 de setembro de 1990. Disponível em: http:// www.planalto.gov.br/ccivil_03/leis/l8080.htm. Acesso em: 18 out. 2019.

BRASIL. Constituição da República Federativa do Brasil de 1988. 05 de outubro de 1988. Brasília-DF: 1988. Disponível em: http://www.planalto.gov.br/ccivil_03/ constituicao/constituicao.htm. Acesso em: 5 out. 2019.

COSTA, E. A. Conceitos e área de abrangência. In: ROZENFELD, S. (Org.). Fundamentos da Vigilância Sanitária. Rio de Janeiro: Editora Fiocruz, 2000. p. 41-8. Disponível em: http://books.scielo.org/id/d63fk/pdf/rozenfeld-9788575413258-05. pdf. Acesso em: 25 mar. 2020.

DE SETA, M. H.; PEPE, V. L. E.; COSTA, E. A. As autoras respondem. Ponto de chegada e de partida: o debate sobre a construção federativa do Sistema Nacional de Vigilância Sanitária. Ciência \& Saúde Coletiva, Rio de Janeiro, v. 15, supl. 2, p. 3320-26, nov. 2010. Disponível em: https://www.scielo.br/scielo.php?script=sci_ arttext\&pid=S1413-81232010000900007\&Ing=pt\&nrm=iso\&tIng=pt. Acesso em: 26 out. 2019.

EMPRESA DE ASSISTÊNCIA TÉCNICA E EXTENSÃO RURAL DO DISTRITO FEDERAL DE MINAS GERAIS [EMATER-MG]. Relatório de Atividades - 2018. Belo Horizonte: EMATER, 2018. Disponível em: http://www.emater.mg.gov.br/doc/intranet/upload/ REL_ATIVIDADE/relatorio_de_atividades_2018_final.pdf. Acesso em: 3 mar. 2019.

ESQUERDO-SOUZA, V. F.; BERGAMASCO, S. M. P. P. Políticas públicas para a agricultura familiar brasileira: um estudo sobre o PRONAF nos municípios do circuito das frutas-SP. Revista Extensão Rural, Santa Maria, v. 22, n. 1, p. 9-35, jan./mar. 2015. Disponível em: https://periodicos.ufsm.br/extensaorural/article/view/14539. Acesso em: 12 out. 2019.

ESTEVAM, D. O.; LANZARINI, J. J. S.; BUSARELLO, A. J. Cooperativas Virtuais e o difícil caminho da legalidade: o caso dos agricultores familiares da Região do Sul do Estado de Santa Catarina. Revista Espaço de Diálogo e Desconexão, Araraquara, v. 5, n. 1, jul./dez. 2012. Disponível em: https://periodicos.fclar.unesp.br/redd/ article/view/5520. Acesso em: 15 out. 2019. 
ESTEVAM, D. O.; SALVARO, G. I. J.; SANTOS, V. J. D. Os desafios da inserção formal de produtos da agricultura familiar no mercado. Redes, Santa Cruz do Sul, v. 23, n. 1, jan./abr. 2018. Disponível em: https://online.unisc.br/seer/index.php/redes/ article/view/11176/pdf. Acesso em: 26 nov. 2019.

FISCHER, A.; MARINI, D.; WINCK, C. A. Percepção das Normas da Vigilância Sanitária pelos agricultores familiares de Joaçaba, Herval D’Oeste e Luzerna. Gestão e Regionalidade, São Caetano do Sul, v. 32, n. 95, p. 108-26, maio/ago. 2016. Disponível em: https://seer.uscs.edu.br/index.php/revista_gestao/article/ view/2898/1945. Acesso em: 12 nov. 2019.

GERMANO, P. M. L.; GERMANO, M. I. S. Higiene e vigilância sanitária de alimentos. 4. ed. Barueri: Manole, 2011.

GRISA, C. As políticas para a agricultura familiar no Brasil: um ensaio a partir da abordagem cognitiva. Desenvolvimento em Debate, Rio de Janeiro, v. 1, n. 2, p. 83-109, 2010. Disponível em: https://revistas.ufrj.br/index.php/dd/article/ view/31915/0. Acesso em: 2 nov. 2019.

INSTITUTO BRASILEIRO DE GEOGRAFIA E ESTATÍSTICA [IBGE]. Censo Agropecuário 2017. IBGE, Rio de Janeiro, 2017. Disponível em: https://censoagro2017.ibge.gov. br. Acesso em: 10 nov. 2019.

KARNOPP, E.; DOEGE, F.; SILVA, J. V. L.; UMANN, V. A. K. Formalidade x informalidade: análise sobre as dinâmicas das agroindústrias familiares do Vale do Rio Pardo (RS, Brasil). Colóquio Revista do Desenvolvimento Regional, Taquara, v. 16, n. 1, p. 5581, jan./jun. 2019. Disponível em: http://seer.faccat.br/index.php/coloquio/article/ view/1200. Acesso em: 10 out. 2019.

KNECHTEL, M. R. Metodologia da pesquisa em educação: uma abordagem teóricoprática dialogada. 1. ed. Curitiba: Intersaberes, 2014.

LAMARCHE, H. (Coord.). A Agricultura familiar: comparação internacional: uma realidade multiforme. Campinas: Unicamp, 1993. V. 1.

MINAS GERAIS (Estado). Secretaria de Estado de Saúde de Minas Gerais [SES/ MG]. Resolução n. 6362, 8 de agosto de 2018. Estabelece procedimentos para o licenciamento sanitário do microempreendedor individual, do empreendimento familiar rural e do empreendimento econômico solidário, que exercem atividades de baixo risco sanitário na área de Alimentos. Belo Horizonte, MG, 2018. Disponível em: https://www.saude.mg.gov.br/images/documentos/ RESOLU\%C3\%87\%C3\%830_\%206362.pdf. Acesso em: 2 nov. 2019. 
MINAS GERAIS (Estado). Lei n. 13.317, de 24 de setembro de 1999. Contém o Código de Saúde do Estado de Minas Gerais. Belo Horizonte, MG, 1999. Disponível em: https://www.almg.gov.br/consulte/legislacao/completa/completa-nova-min. html?tipo=Lei\&num=13317\&ano=1999. Acesso em: 12 nov. 2019.

MOREIRA, F. M. Recuperação de dados da operacionalização de programas governamentais: um estudo do Programa Nacional de Fortalecimento da Agricultura Familiar. 2015. Dissertação (Mestrado em Ciência da Informação) Universidade Estadual Paulista Júlio de Mesquita Filho, Marília, SP, 2015. Disponível em: https://repositorio.unesp.br/bitstream/handle/11449/128093/000850431. pdf?sequence=1\&isAllowed=y. Acesso em: 15 nov. 2019.

ORGANIZAÇÃO DAS NAÇÕES UNIDAS [ONU]. Transformando nosso mundo: a agenda 2030 para o Desenvolvimento Sustentável. ONU, [s.I.], 2015. Disponível em: https://nacoesunidas.org/wp-content/uploads/2015/10/agenda2030-pt-br. pdf. Acesso em: 10 out. 2019.

SCHOTTZ, V.; CINTRÃO, R. P.; SANTOS, R. M. Convergências entre a Política Nacional de SAN e a construção de normas sanitárias para produtos da Agricultura Familiar. Revista Vigilância Sanitária em Debate, Rio de Janeiro, v. 2, n. 4, p. 115-23, nov. 2014. Disponível em: https://visaemdebate.incqs.fiocruz.br/index.php/visaemdebate/ article/view/461. Acesso em: 2 dez. 2019.

TOMASETTO, M. Z. C.; LIMA, J. F.; SHIKIDA, P. F. A. Desenvolvimento local e agricultura familiar: o caso da produção de açúcar mascavo em Capanema-Paraná. Revista Interações, Campo Grande, v. 10, n. 1, p. 21-30, jan./jun. 2009. Disponível em: https://www.interacoes.ucdb.br/interacoes/article/view/399. Acesso em: 2 dez. 2019.

VEIGA, J. E. Agricultura familiar e sustentabilidade. Cadernos de Ciência e Tecnologia, Brasília, v. 13, n. 3, p. 383-404, set./dez. 1996. Disponível em: https://seer.sct. embrapa.br/index.php/cct/article/view/9009. Acesso em: 2 nov. 2019.

WILKINSON, J.; MIOR, L. C. Setor informal, produção familiar e pequena agroindústria: interfaces. Estudos Sociedade e Agricultura, Rio de Janeiro. v. 7, n. 2, seção 13, p. 29-45, out. 1999. Disponível em: https://revistaesa.com/ojs/index. php/esa/article/view/159. Acesso em: 26 out. 2019. 
